\title{
Complete esophageal obstruction following endoscopic variceal ligation: a case report and literature review
}

This article was published in the following Dove Press journal:

Clinical and Experimental Gastroenterology

\author{
Jan Kubovy \\ Tom D Boswell \\ Guy Vautier \\ Malcolm M Arnold \\ Department of Gastroenterology, \\ Hawkes Bay Hospital, Hastings, New \\ Zealand
}

\begin{abstract}
Endoscopic variceal ligation (EVL) is an important treatment modality in managing complications of portal hypertension. Since its advent 30 years ago, the procedural complications have decreased significantly, especially when compared with variceal sclerotherapy. With the current widespread use of EVL, rare complications are now becoming increasingly recognized. We present a case of complete esophageal obstruction, its management, and clinical course. Our literature review identified only eight reported cases. We compare the varied treatment approaches and outcomes in the cited articles.
\end{abstract}

Keywords: portal hypertension, esophageal varices, endoscopic variceal ligation, esophageal obstruction

\section{Introduction}

Portal hypertension of any etiology can be associated with esophageal varices. This carries a risk of bleeding. Endoscopic variceal ligation (EVL) is currently regarded as the treatment of choice for both esophageal variceal bleed prophylaxis as well as acute hemostasis. ${ }^{1,2}$ Although EVL is considered to be a safe intervention, complications can and do occur. ${ }^{3}$ The most common are postprocedural pain, dysphagia, delayed ulcer bleeding, and chronic esophageal strictures. ${ }^{4}$ We present a particularly rare complication, a case of complete esophageal obstruction. We also compare the varied management approaches and their outcomes of the very few cases found in published literature. We hope this may provide a reference point for clinicians facing this rare and challenging complication.

\section{Case report}

This patient has provided written informed consent in regard to publishing her case.

A 62-year-old Caucasian woman underwent elective EVL as primary prophylaxis. Her portal hypertension was related to seronegative autoimmune liver disease with cholangiopathy (baseline Model for End-stage Liver Disease score-7, all values within normal limits). Comorbidities included ulcerative colitis, mild chronic obstructive pulmonary airway disease, and recurrent deep venous thrombosis. Relevant pharmacotherapy included ursodeoxycholic acid, 6-mercaptopurine, mesalazine, omeprazole, and propranolol (only able to tolerate low dose due to excessive fatigue).

Surveillance esophago-gastro-duodenoscopy (OGD) demonstrated variceal formation ( 3 columns of grade 2 varices, all $>5 \mathrm{~mm}$ in size) despite the above beta-blocker regimen, and a decision was made for endoscopic ablation.
Correspondence: Jan Kubovy Department of Gastroenterology, Hawkes Bay Hospital, 398 Omahu Rd, Hastings 4I20, New Zealand Email dr.jan.kubovy@gmail.com 
The OGD resulting in the complication under discussion took place 4 weeks after application of two bands on two separate varices. This second procedure showed a single remaining varix in the 2 o'clock position without obvious scarring, but perhaps with a minor narrowing of the distal esophagus (Figure 1). The remaining varix was banded $2 \mathrm{~cm}$ above the gastro-esophageal junction (GOJ) applying a single band using Saeed Multi-band Ligator 6-shooter (MBL-U-6, Cook Medical).

The patient developed severe retrosternal pain followed by retching and vomiting in the recovery room. This was successfully managed with antiemetics and analgesia, and she was discharged pain-free and without nausea or vomiting.

She presented 3 days later to the emergency department with chest pain and aphagia (unable to tolerate even sips of water).

Serum biochemistry indicated acute kidney injury, and her chest X-ray was unremarkable.

The initial management was conservative as further intervention was considered too risky. Treatment included intravenous fluids, omeprazole, antiemetics, and a trial of dexamethasone. As there was no symptomatic improvement on day 3 of her admission ( 6 days after the procedure), further OGD was performed. The findings were of a nubbin of necrotic tissue encased by a visible band in the distal esophagus and a small amount of food residue above it (Figure 2). The lumen was not able to be identified. A computed tomography scan of

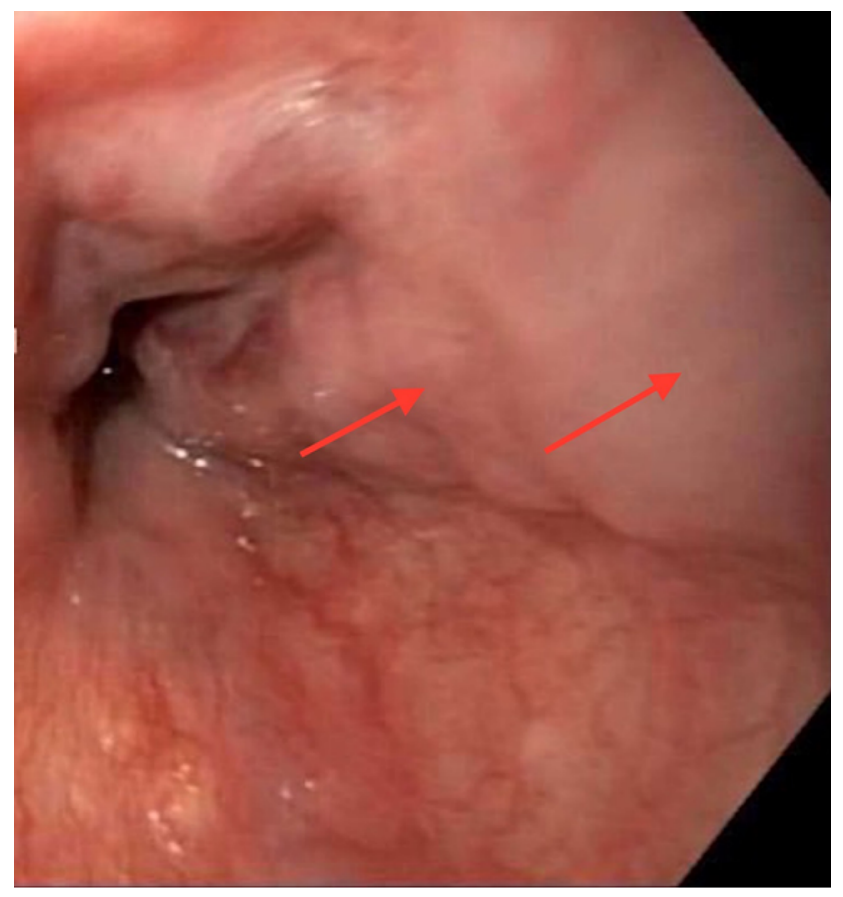

Figure I Index OGD showing a single remaining varix in 2 o'clock position. Notes: Arrows indicate the culprit varix prior to banding. Abbreviation: OGD, esophago-gastro-duodenoscopy. her chest demonstrated distal esophageal wall thickening and a soft tissue nodule (likely representing the banded varix) just above the GOJ, but without other complications (Figure 3).

Total parenteral nutrition was established via a peripherally inserted central catheter. Progress thereafter was slow with a negligible oral fluid intake on day 17 , barium swallow at that time indicating delayed esophageal clearance with an underlying stricture (Figure 4). Further complications during the admission occurred, namely, peripherally inserted central catheter-related deep venous thrombosis and exacerbation of ulcerative colitis. Total parenteral nutrition was discontinued after 14 days. Total length of stay was 20 days.

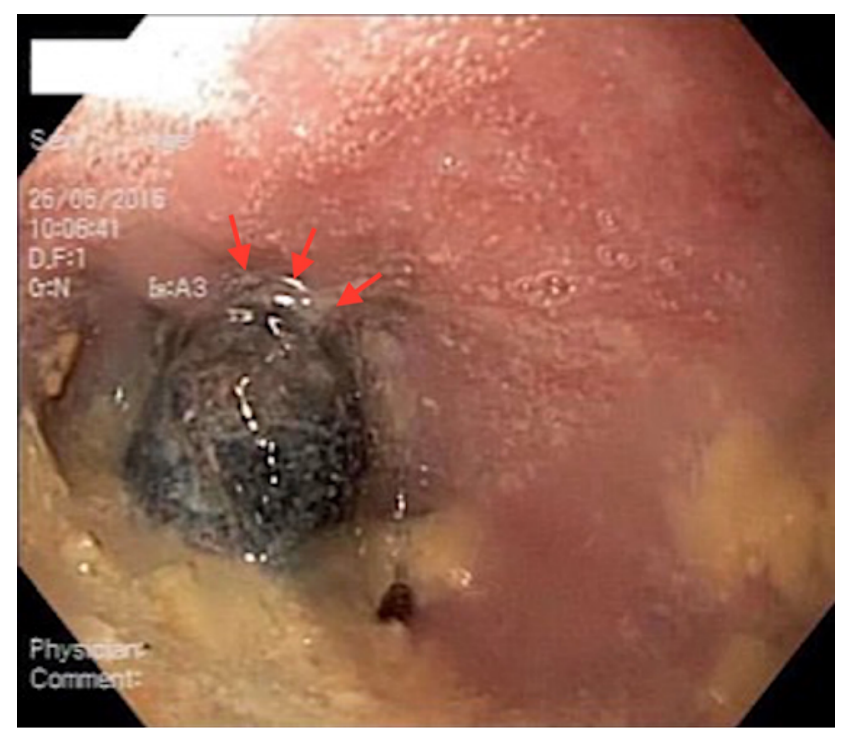

Figure 2 Necrotic banded varix in 2 o'clock position with some food residue. Note: The arrows indicate the position of the band.

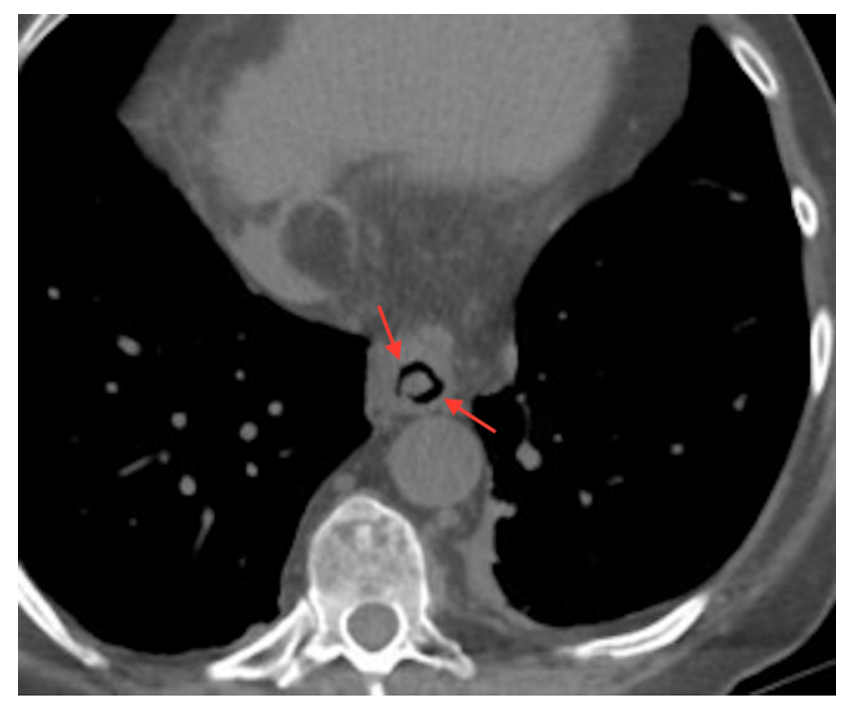

Figure $3 \mathrm{CT}$ chest demonstrating soft tissue nodule in distal esophagus, likely representing banded varix.

Note: Arrows indicate the soft tissue nodule within distal esophagus. Abbreviation: CT, computed tomography. 
Repeat OGD 42 days after the procedure revealed a patent esophagus with a mild stricture and a semicircular scar just above the GOJ (Figure 5).

\section{Discussion}

Complete esophageal obstruction as a complication of EVL is exceedingly rare. Our literature search identified only eight cases of this since the advent of EVL 30 years ago..$^{5-12}$

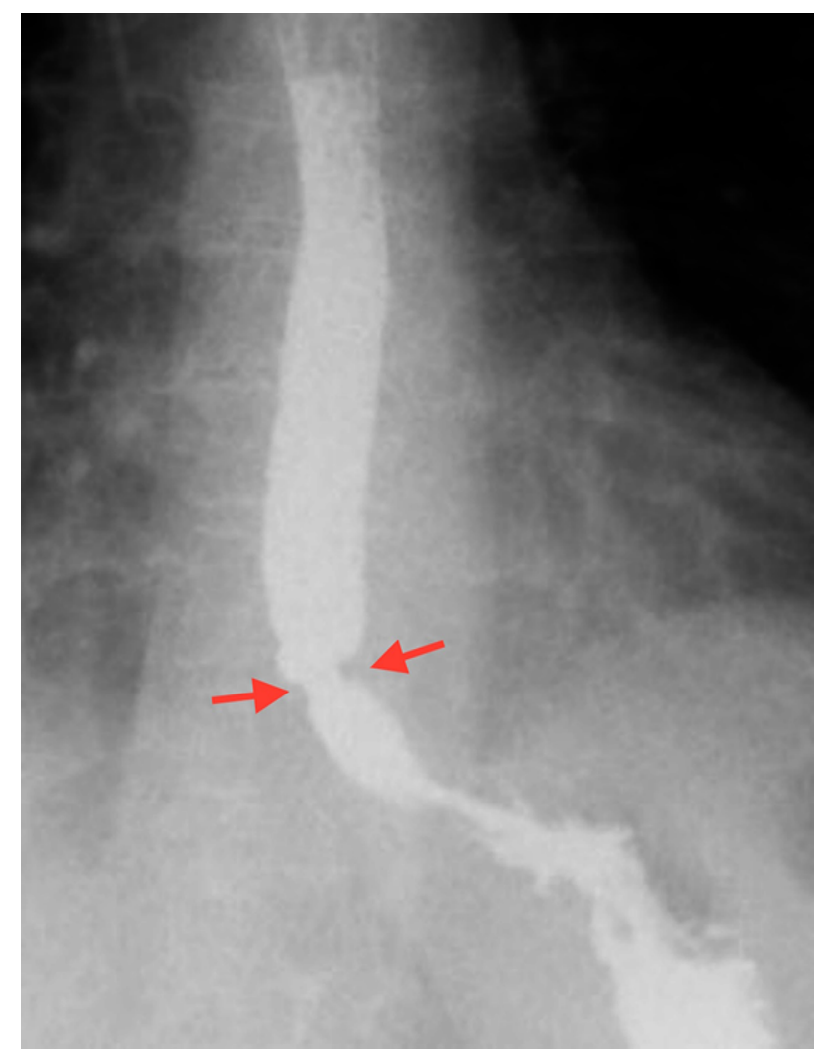

Figure 4 Distal esophageal stricture seen on barium swallow study on day 17. Note: The arrows indicate distal esophageal stricture.

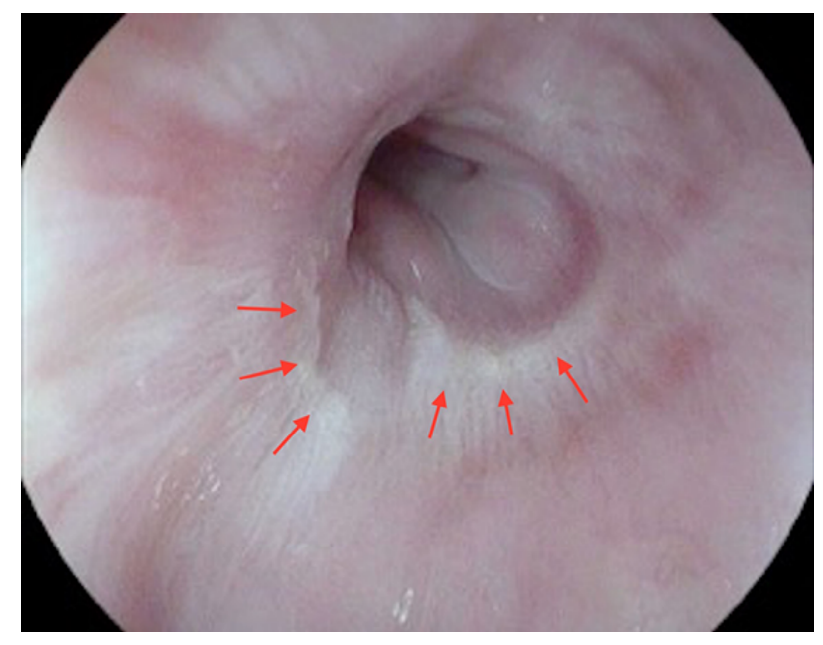

Figure 5 Semicircular scar in distal esophagus 42 days after the index procedure. Note: The arrows indicate the scar.
The mechanism is thought to be multifactorial: a large engorged banded varix causing a "plug"; excessive use of suction resulting in extra-variceal mucosal encasement; or even banding opposing walls of esophagus; surrounding tissue edema; impaired lower esophageal sphincter relaxation; altered esophageal motility post EVL; hematoma; and predisposing underlying esophageal stricture from previous banding.

In our case, we believe the obstruction may have been caused by encasing a large portion of the surrounding mucosa as well as the varix on a background of chronic stricture related to previous EVL.

The available literature experience regarding appropriate management of this complication is divided between conservative and urgent intervention. ${ }^{5-12}$

The conservative approach is based on the premise that this is likely to be a self-limiting condition, with an emphasis on supportive care alone. ${ }^{5-8}$ The average time until the resumption of liquid diet was 4 days.

Advocates of urgent reintervention aim to dislodge/ remove the variceal band mechanically, thus relieving the obstruction. Several such methods have been applied: a "bottle opener" technique with a capped endoscope; 9 a simple band dislodgement with the tip of the scope ${ }^{10}$ the use of biopsy forceps, rat-tooth forceps or hot biopsy forceps, ${ }^{11,12}$ or a reusable loop cutter. ${ }^{12}$

It is conceivable that further complications may arise from these procedures. Successful removal of the band and resolution of the obstruction was achieved in three out of the four interventional cases. One case, however, was complicated by a $6 \mathrm{~cm}$ intramural esophageal dissection and bleeding (this was managed conservatively). ${ }^{11}$

We perceive the risk-benefit ratio to be in favor of the conservative approach.

Nonetheless, early intervention may be more costeffective if successful, thus potentially avoiding prolonged hospital admission with further complications, as demonstrated in our case.

Only the most experienced endoscopists should attempt to intervene in this scenario.

\section{Conclusion}

EVL-related complete esophageal obstruction is very rare. Recognition of possible precursors, especially underlying luminal narrowing, may aid in the prevention of this complication. The risk-benefit and cost-effectiveness of early interventional versus conservative management is unclear at this point. 


\section{Disclosure}

The authors report no conflicts of interest in this work.

\section{References}

1. Thiele M, Krag A, Rohde U, Gluud LL. Meta-analysis: banding ligation and medical interventions for the prevention of rebleeding from oesophageal varices. Aliment Pharmacol Ther. 2012;35(10):1155-1165.

2. Lo GH, Lai KH, Cheng JS, et al. A prospective, randomized trial of sclerotherapy versus ligation in the management of bleeding esophageal varices. Hepatology. 1995;22(2):466-471.

3. Schmitz RJ, Sharma P, Badr AS, Qamar MT, Weston AP. Incidence and management of esophageal stricture formation, ulcer bleeding, perforation, and massive hematoma formation from sclerotherapy versus band ligation. Am J Gastroenterol. 2001;96(2):437-441.

4. Rai RR, Nijhawan S, Singh G. Post-ligation stricture: a rare complication. Endoscopy. 1996;28(4):406.

5. Nikoloff MA, Riley III TR, Schreibman IR. Complete esophageal obstruction following endoscopic variceal ligation. Gastroenterol Hepatol. 2011;7(8):557.
6. Elizondo-Rivera RL, González-González JA, Garcia-Compean D, Maldonado-Garza HJ. Complete esophageal obstruction after endoscopic variceal band ligation. Endoscopy. 2014;46(Suppl 1): E457-E458.

7. Dilshad A, Ahmad I, Niazi AK, Zubair M, Khalid U. Severe dysphagia after endoscopic variceal band ligation: a case report. Proceeding S.Z.P.G.M.L. 2003;17(2):91-92.

8. Saltzman JR, Arora S. Complications of esophageal variceal band ligation. Gastrointest Endosc. 1993;39(2):185-186.

9. De Melo SW. Complete esophageal occlusion after band ligation. Endoscopy. 2011;43(S 02):E259.

10. Sarwar FC, Batul MB. Complete esophageal occlusion following esophageal variceal band ligation: an unusual complication; a case report. Visible Hum J Endosc. 2010;9(1).

11. Chahal H, Ahmed A, Sexton C, Bhatia A. Complete esophageal obstruction following endoscopic variceal band ligation. J Community Hosp Intern Med Perspect. 2013;3(1):20043.

12. Kwiatt JT, Merchant P. Successful removal of an esophageal band causing complete esophageal obstruction after variceal ligation. Gastrointest Endosc. 2016;83(5):1030-1031.
Clinical and Experimental Gastroenterology

\section{Publish your work in this journal}

Clinical and Experimental Gastroenterology is an international, peerreviewed, open access, online journal publishing original research, reports, editorials, reviews and commentaries on all aspects of gastroenterology in the clinic and laboratory. This journal is included on PubMed. The manuscript management system is completely online

\section{Dovepress}

and includes a very quick and fair peer-review system, which is all easy to use. Visit http://www.dovepress.com/testimonials.php to read real quotes from published authors. 